\title{
EN NOMBRE DEL REY. EXEQUiAS EN GOA Y MANILA A MEDIADOS DEL SIGLO XVIII
}

\author{
Pedro Luengo
}

Universidad de Sevilla

Resumen: En el presente estudio se ofrece un análisis artístico de las exequias realizadas en honor del papa Benedicto XIII y el gobernador Gaspar de la Torre, en el ámbito manileño; y del virrey Luis de Meneses y del inquisidor Nunho de Ataíde en Goa. Interesan como ejemplos del desarrollo artístico de ambas ciudades, además de permitir la comparación entre la recepción de los modelos occidentales por medio de dos rutas marítimas distintas como eran la portuguesa y la hispana. Seguramente la lejanía de estos enclaves respecto a Europa llevó a intensificar la publicación tanto de las exequias, como de otras fiestas celebradas durante el siglo XVIII, con objeto de llamar la atención de las respectivas metrópolis. Por otro lado, su estudio permite abordar la asimilación de modelos artísticos y literarios europeos en Asia.

Palabras clave: arquitectura efímera, Gaspar de la Torre, Luis de Meneses, Fernando Valdés y Tamón.

ABSTRACT: The present paper provides an artistic analysis of the funerals held on the one hand in honor of Pope Benedict XIII and Governor Gaspar de la Torre, both in Manila, and on the other hand Viceroy Luis de Meneses and the inquisitor Nunho de Ataíde in Goa. All of them can be considered as examples of the artistic development of both cities, and allows comparing the reception of Western models through two different Asiatic routes as the Portuguese and the Spanish. Surely the distance between these cities and Europe increased interest in the publication of funerals and other celebrations held during the eighteenth century, in order to claim the attention of the metropolis. Finally the study provides information about the assimilation of the European artistic and literary models in Asia. 
Keywords: Ephemeral Arquitecture, Gaspar de Meneses, Luis de Meneses, Fernando Valdés y Tamón.

$\mathrm{E}$ l desarrollo de las arquitecturas efímeras de carácter funerario en la capital del archipiélago filipino ha sido tratado escasamente a pesar de la documentación gráfica y escrita que se conserva de las honras dedicadas no solo a monarcas, sino también a otros personajes claves en la historia de Filipinas ${ }^{1}$. Más llamativo aún es el silencio sobre las fiestas de distinta índole celebradas en una capital virreinal de la importancia de Goa. ${ }^{2}$ A pesar de ello, parece lógico pensar que la lejanía de ambas ciudades de sus respectivas metrópolis obligaría a potenciar las fiestas en razón de nacimientos, matrimonios y fallecimientos de miembros de la familia real como instrumento de propaganda dinástica y reafirmación de la fidelidad de sus súbditos. A estas y a las correspondientes a las autoridades religiosas, caso de las honras por los papas, además de otras celebraciones como las beatificaciones, hay que añadir un capítulo poco tratado por la historiografía y especialmente significativo en estos confines imperiales. Se trata de los funerales por los gobernadores filipinos y por los virreyes o gobernadores de Goa, quienes se apropiaron de las honras funerarias reservadas a la corona, cuando fallecieron en el ejercicio de su cargo, lo que por otra parte no fue habitual.

A mediados del siglo XVIII coinciden varias celebraciones funerarias, tanto en Goa como en Manila, de las cuales existe constancia documental. Sin embargo, no fueron las primeras ya que las precedieron las exequias manileñas a Luis I en 1721, y las del papa Benedicto XIII en 1733, celebrada esta ya durante el periodo como gobernador de Fernando Valdés y Tamón (1729-1739). ${ }^{3}$ Su sucesor en el cargo, Gaspar de la Torre fallecería en Manila en 1745, y sus exequias formarían parte del conjunto de celebraciones fúnebres antes aludido. ${ }^{4}$ Un año más tarde moriría en Madrid el rey Felipe V, y con tal mo-

1. La aportación más moderna en esta línea es la de Mejías Álvarez, María Jesús: «Túmulo de María Amalia de Sajonia en Filipinas» en Morales, Alfredo J. (coord.): Filipinas, puerta de Oriente. De Legazpi a Malaspina, San Sebastián-Manila, Lunwerg-SEACEX, 2004. p. 227. A esta habría que añadir con un sentido más general Coello de la RosA, AlexAndre: «El Fénix en las Marianas (1747)» en Revista de Indias, 2010, vol. LXX, n. ${ }^{\circ} 250$, pp. 779-808.

2. Las de José I quedan recogidas en Mártires Lopes, Maria de Jesus dos: Goa Setecentista. Tradiçao e Modernidades (1750-1800), Lisboa, Universidade Católica Portuguesa, 1996.

3. Llanto de los astros en el ocaso del sol... Benedicto XIII que en... honrosas exequias celebró el sagrado firmamento dominicano en la ciudad de Manila. Manila: Nuestra Señora de los Ángeles, 1733. Biblioteca Pública del Estado. Orihuela. Signatura 5733.

4. El personaje ha sido estudiado en Rodríguez García, Vicente: El gobierno de don Gaspar Antonio de la Torre y Ayala en las Islas Filipinas, Granada, Universidad de Granada, 1976. 
tivo se erigió la lógica pira funeraria en la capital del archipiélago en $1748 .^{5}$ Posterior es el ya conocido y estudiado túmulo en honor a María Amalia de Sajonia, de $1762 .{ }^{6}$ Junto a estas honras fúnebres hay que tener en cuenta otras celebraciones de carácter festivo coetáneas. ${ }^{7}$

Uno de los aspectos de mayor interés de la documentación que recogen estas celebraciones es la circulación de modelos artísticos y microarquitectónicos desde las respectivas metrópolis hasta estos enclaves de Oriente. ${ }^{8}$ En estos procesos de transferencia no puede olvidarse el papel destacado que desempeñaron territorios como Nueva España o Brasil que pueden servir para facilitar el estudio de los casos de Manila o Goa. ${ }^{9}$ De hecho, al analizar cualquier túmulo regio barroco erigido en una ciudad peninsular, en México y en Manila, debe recordarse la enorme vinculación existente entre las dos últimas, así como la lejanía de ambas respecto a la metrópoli. Por ello el estudio de las creaciones americanas resulta de radical importancia para comprender mejor las filipinas. ${ }^{10}$

5. Mesquida, JoAquín: La perla del Oriente derretida en llanto y llanto elevado a perla fina de lealtad en las sentidas expresiones del dolor amante, con quela muy noble, y muy leal ciudad de Manila celebró las reales exequias a la inmortal memoria de su querido católico monarca Don Philippo V, Manila, De la Cruz, 1748. De esta obra solo se conoce la catalogada en la Biblioteca Estatal de Baviera, desgraciadamente desaparecida en los últimos años por lo que no ha podido consultarse el grabado. De la Maza debió trabajar con otro ejemplar, quizás en México, que tampoco ha sido localizado. La única reproducción moderna, a partir de la cual se ha elaborado este estudio se encuentra en GARCía DíAz, TARSICıO: «Tesis filipina del siglo XVIII» en Anales de historia, vol. v, México, unam, 1965, pp. 99-141. Por último, se ha localizado una copia en la Biblioteca Nacional de Filipinas, con signatura.

6. En el Archivo de Indias (AGI) se conservan dos ejemplares de este grabado de Laureano Atlas en Mp, Filipinas, 45 y Mp-Estampas, 143. Mejías Álvarez, María Jesús: «Túmulo de María Amalia de Sajonia en Filipinas» en Morales, Alfredo J. (coord.): Filipinas puerta de oriente, p. 227. Mejías Álvarez, MaríA Jesús: Fiesta y Muerte Regia. Las estampas de túmulos reales del Archivo General de Indias, Sevilla, EEHA, 2002.

7. Aunque con menor información sobre las celebraciones realizadas, también en estos años centrales del siglo tuvieron lugar las exequias manilenses por María Bárbara de Portugal (1758), o las correspondientes a la exaltación al trono en 1748 de Fernando VI. A todo ello habría que añadir múltiples fiestas correspondientes a matrimonios reales, o en el ámbito religioso a beatificaciones que sirven para conocer el proceso evolutivo de tales festejos, así como lo habitual reutilización de materiales en las estructuras efímeras de la Manila barroca. Fuera del archipiélago, aunque muy próxima a su contexto cultural se encuentran las Islas Marianas, donde se tiene constancia de la celebración de honras de carácter bastante humilde tras la muerte de Felipe V, que recientemente han sido sacadas a la luz. CoELLO DE LA Rosa, Alexandre, «El Fénix en las Marianas».

8. Un intento en este sentido puede verse en distintos artículos como Allo Manero, Adita: «Aportación al estudio de las exequias reales en Hispanoamérica. La influencia sevillana en algunos túmulos limeños y mejicanos», Anuario del Departamento de Historia y Teoría del Arte, 1, 1989, pp. 121-137.

9. Para conocer la producción novohispana debe consultarse Morales Folguera, José Miguel: Cultura simbólica. Arte efímero en Nueva España, Sevilla, Junta de Andalucía, 1991. Otro texto anterior es el de MAZA, Francisco DE la: «Las piras funerarias en la historia y en el arte de México», Anales del Instituto de Investigaciones Estéticas, México, 1946.

10. Al respecto se tienen noticias sobre varios túmulos reales caso del correspondiente a Luis I en México (1717), a Felipe V en Quito, Panamá y Guatemala (1747), a María Bárbara de Portugal en México y Oaxaca (1759) y a María Amalia de Sajonia en México y Lima (1761). Por otra parte, debe señalarse que Santiago de Querétaro levantó en 1744 un túmulo al marqués de Villar del Águila en reconocimiento a sus obras hidráulicas, lo que debe ser tenido en cuenta al analizar las piras filipinas en honor de personajes de la administración y gobierno. Sobre este tipo de piras de menor rango debe destacarse las conservadas en Santa Prisca (Taxco) o la del Carmen, actualmente en el Museo de Bellas Artes de Toluca. Cfr. Mínguez, Víctor: «Efímero Mestizo» en AA. vv.: Iberoamérica mestiza. Encuentro de pueblos y culturas, Madrid, SEACEX, 2003. 
Morales Folguera ya planteó una evolución formal de los túmulos funerarios novohispanos a lo largo del siglo XviII. ${ }^{11}$ Desde unos primeros formatos piramidales, se pasó a mediados de siglo a microarquitecturas en forma de templos, para finalmente optar por estructuras monumentales que resguardaban el féretro, en cierto sentido fusionando las dos propuestas previas. ${ }^{12}$ Como también indica este investigador lo interesante en el caso mexicano es el programa iconográfico, mientras que la arquitectura queda ligada a las prácticas contemporáneas habitualmente desfasadas con respecto a la metrópoli. En el caso concreto de las honras fúnebres, estos planteamientos se pueden trasladar con facilidad al caso filipino.

En las primeras décadas del siglo Xviı Manila vivió uno de sus momentos culturales más brillantes con figuras como Pedro Murillo Velarde o el gobernador Fernando Valdés y Tamón, quienes tuvieron una especial actuación en las fiestas y funerales de la época. El último vendría también a revolucionar la imagen social que ofrecía el máximo representante de la corona en el archipiélago. ${ }^{13}$ Valdés comenzaría a ser considerado por la sociedad del momento como una especie de gobernador sol, haciendo propia la iconografía astral vinculada al monarca incluso durante su vida. ${ }^{14}$ Por ejemplo, el Sol Valdés presidió desde el balcón del Palacio Real las fiestas por el matrimonio entre el príncipe Fernando y María de Portugal (1731). ${ }^{15}$ Con ello generó una imagen que algunos de los gobernadores posteriores reutilizarían. Como ha sido apuntado esta asimilación al astro rey resulta muy evidente en relación con la monarquía hispana, tal y como recogen distintos autores. ${ }^{16}$

Pero no quedó ahí la apuesta de Valdés por exaltar la imagen del gobernador, una propuesta que pareció trasladar a su hijo y homónimo. El Sol Valdés, es decir Fernando Valdés y Tamón, no murió en Filipinas sino en México, más concretamente en Cuernavaca según indica Murillo Velarde, impidiendo lo que habrían sido unas interesantes exequias oficiales donde su iconografía solar

11. Morales Folguera, Cultura simbólica, p. 22.

12. Entre otros escritos de este autor puede destacarse en este sentido Morales Folgueras, José Miguel: «Los programas iconográficos en el arte funerario mexicano», Cuadernos de Arte e Iconografía, Tomo II, 4, 1989.

13. Recientemente se ha leído una tesis doctoral donde se abordan distintos rasgos de la personalidad polifacética de este personaje. Desgraciadamente se pasa por alto la imagen generada en la literatura de la época, así como su importante labor cartográfica y constructiva. BARRIO MuÑoz, José ÁNGEL DEL: Fernando Valdés y Tamón. Gobernador General de Filipinas (1729-1739), tesis doctoral inédita, Madrid, UNED, 2010.

14. En uno de los pasajes llega a afirmarse que: «la nobleza de los Valdeses, no solo brilla en España como el oro de los quilates más subidos de las Asturias».

15. A lo largo del texto pueden extraerse distintas referencias al gobernador en este sentido: «En Palacio se vio Campo de luces, en que radiante hermoso está luciendo/ el Sol Valdés, que ilustra con sus rayos / de aquestas islas todo el hemisferio». O bien «Ya estaba en su balcón / el Sol de aqueste emporio, Gran Tamón». Cfr. Descripción de las fiestas reales con que la muy noble y siempre fidelísima ciudad de Manila... celebró los felices desposorios de... Don Fernando, príncipe de Asturias, con la señora infanta de Portugal Doña María. Manila: Compañía de Jesús, 1731.

16. Véase el estudio al respecto de Mínguez, Victor: Los reyes solares: iconografía astral de la monarquía hispánica, Castellón, Universitat Jaume I, 2001. 
seguramente sería subrayada. Su hijo, al poco de la vuelta a la corte madrileña contrajo matrimonio y trasladó su residencia a Molina de Aragón (Guadalajara), donde levantaría lo que hoy es conocido como el Palacio del Virrey de Manila. Aunque fuera obra de su hijo, el cargo de virrey nunca existió en el archipiélago frente a lo que apuntan algunos autores, pero ciertamente Valdés creó una imagen barroca del cargo que parecía circunscrita a los monarcas y su familia, y por representación de aquellos a los virreyes, nunca a los gobernadores. ${ }^{17}$

Aunque se tienen noticias sobre fiestas y exequias en Manila, desde fechas muy tempranas, serán las de la década de los veinte y treinta del siglo XVIII las que más claramente ofrezcan la recepción de los modelos barrocos, como queda de manifiesto en los grabados que de ellas se realizaron. Al respecto hay que señalar las correspondientes al malogrado Luis I, cuya subida al trono y prematuro fallecimiento fueron conocidas en Manila en el mismo momento. ${ }^{18}$ A este habría que añadir las del obispo de Oviedo, Manuel José de Hendaya y Haro (Manila, 1674-Benavente, 1729), natural de Filipinas y persona muy valorada en el archipiélago. ${ }^{19}$ Los sermones fúnebres en honor a «el chinito», entonces recién nombrado Arzobispo de México, cargo del que no llegó a tomar posesión, fueron publicados en Manila por la intercesión del gobernador, originario de Oviedo. ${ }^{20}$ En ellos las alusiones a este personaje son numerosas, y siempre retoman la metáfora solar, tan propia de la literatura novohispana de este tipo dedicada a la muerte de reyes. ${ }^{21}$

Además de exequias reales y al arzobispo mencionado, la capital filipina tuvo que celebrar las honras por la muerte del papa Benedicto XIII en $1733 .{ }^{22}$

17. Herrera Casado, Heráldica Molinesa, p. 69. Véase también de este autor Palacios y casonas de Castilla-La Mancha, Guadalajara, 2004. La discusión sobre el origen del Palacio del Virrey ha sido zanjada recientemente en BARrio MuÑoz, Fernando Valdés, pp. 10-21.

18. Entre los túmulos funerarios realizados en Manila en el siglo xviı será el mausoleo levantado en honor a Luis I el descrito más pormenorizadamente. La descripción de este túmulo funerario establece claros parentescos con otras obras de arte filipinas. En primer lugar se planteó una estructura arquitectónica de planta octogonal decorada con distintas pinturas. La apuesta por la columna salomónica será lo habitual en el archipiélago, tanto en las primeras décadas del siglo como después de su primera mitad. Aunque llegó con cierta rapidez, el estípite no fue adoptado de forma generalizada como sí lo fue en el resto de Nueva España. Otro elemento a destacar, y que comparte con el mundo luso, es la difusión de las tarjas que mantendrán su protagonismo en las estructuras funerarias filipinas durante gran parte del siglo. Por todo esto, las descripciones de este tipo de aparatos festivos pueden ayudar a datar el amplísimo patrimonio de retablos conservado en Filipinas del que se conoce aún escasísima documentación, caso similar a lo que ocurre en Goa. Real Mausoleo que a la inmortal memoria de su católico monarca Luis I erigió en sus solemnes exequias la muy noble y leal ciudad de Manila. Manila: Universidad de Santo Tomás, 1726. A esta publicación, donde aparece descrito el túmulo regio, habría que añadir la carta que el gobernador envió a la metrópoli sobre estas honras, haciendo mención de la colocación de un retrato de cuerpo entero del monarca en el balcón del Ayuntamiento, así como sobre la construcción del túmulo. AGI, FILIPINAS, 141, N. 11. F. 12r, 15v.

19. En este sermón se juega con la idea de hacer un monumento escultórico que recuerde la valía del difunto. Por ello las referencias artísticas son muy numerosas aunque muy probablemente no se refiere a una descripción de esculturas efímeras. Estatua de verdadera grandeza dibujada... de... Manuel José de Endaya y Aro, Manila, 1731.

20. BARrio MuÑoz, Fernando Valdés, p. 2.

21. Mínguez, Víctor: Los reyes distantes: imágenes del poder en el México virreinal, Castellón, Universitat Jaume I, 1995.

22. Llanto de los astros en el ocaso del sol. 
Se trata de la única estructura funeraria realizada en Manila para un papa de la que se haya conservado representación gráfica. Afortunadamente, a esto hay que añadir que la publicación de las celebraciones incorpora la imagen más antigua conocida de un túmulo filipino. Pero además de estas singularidades, la estructura merece especial atención por servir de enlace entre la empleada con motivo de la muerte de Luis I y las erigidas en la década de los cuarenta.

Se trata de una base cuadrada sobre las que se desarrollan dos cuerpos arquitectónicos con representaciones de virtudes o emblemas, y articulados por columnas salomónicas. Si bien es cierto que su uso se extendería en Manila hasta bien entrada la segunda mitad del siglo xviıI, tanto el modelo para estas columnas como para las tarjas muestran una clara vinculación con otras dos estructuras ya conocidas como son el retablo mayor del Convento de San Francisco de las Lágrimas de Manila, realizado en la década de los cuarenta del siglo XVIII, o el retablo de la portería del mismo complejo datado en $1756 .{ }^{23}$ Frente a esta similitud hay que destacar la diferencia con otras columnas salomónicas coetáneas como son las del retablo dedicado a San Nicolás Tolentino, fechado en 1750, aún conservado en el Convento de San Agustín de Manila; o incluso con las del retablo de la sacristía del citado Convento de San Francisco.

Continuando con la descripción de la estructura, en el primer cuerpo se ubica el catafalco, subrayando el carácter templario de la estructura. El parecido, tanto estructural como en la elección de algunos temas, con el túmulo realizado en México para Luis I, seguramente basado en el anterior a Luis XIV, es muy evidente. Esto hace pensar que la tardía llegada a Manila de la noticia de la muerte del monarca permitió servirse de las directrices planteadas en el túmulo de la capital novohispana. ${ }^{24}$

Incluso en esta estructura la simbología astral queda patente. Está rematada por un sol, mientras que en el frente de la base ofrece representaciones de Aries, a la izquierda, y Tauro, a la derecha. En los costados restantes se representaron, en el lado derecho, Géminis, Leo, Libra y Sagitario, mientras en el izquierdo, aparecían Cáncer, Virgo, Escorpio y Capricornio. Para el lado frontero se dejaron Acuario y Piscis. En el primer cuerpo se situaron representaciones de las musas, más concretamente de Clío y Urania en el frente principal, y en el posterior de Euterpe y Talia. Encarando los costados se colocaron en parejas Polimnia y Erato, en un lado, y, en el otro, Terpsícore y Calíope. De esta forma aparecían todas las musas dejando libre el espacio central para permitir la contemplación del féretro.

23. Luengo, Pedro: Intramuros: Arquitectura en Manila, 1739-1762, Madrid, Fundación Universitaria Española, 2012, pp. 308 y 316. El retablo fue encargado por Francisco de Yugo para su enterramiento. Cfr. Archivo Franciscano Î́bero-Oriental 86/2.

24. Las honras fúnebres solían celebrarse en Manila con varios años de retraso con respecto a la península ibérica e incluso con México. 
La representación de Melpómene pasaba al tercer cuerpo, presidiendo la estructura en el nicho central. ${ }^{25}$ La musa aparece como una joven sentada, cuya cabeza reposa en su brazo izquierdo, conforme a un modelo iconográfico que recuerda al pequeño Buen Pastor del arte indoportugués. ${ }^{26}$ Se trataría pues de un ejemplo de reutilización iconográfica de un modelo que participa por igual de la tradición oriental y de la occidental. Es más, podría aventurarse un trasfondo interpretativo de más calado al tener en cuenta que la base iconográfica oriental es el Buda Maitreya, el Buda del futuro. Con independencia de ello no parece quedar duda de que los artesanos chinos que levantaron esta estructura reaprovecharon sus propios modelos. Finalmente, acompañando a esta última musa se representaron siete signos celestes, o más concretamente: Luna, Mercurio y Venus en un lado; Marte, Júpiter y Saturno en otro, mientras que el Sol quedaba frente al altar. ${ }^{27}$

A toda la estructura habría que añadir otros elementos como son la mitra y el bonete soportado por pequeños atlantes y bajo ellos el perro de santo Domingo con la antorcha. Solo en este elemento, que pasa desapercibido en un primer vistazo, queda patente la vinculación del túmulo con sus promotores, los dominicos, orden a la que pertenecía el papa fallecido. En el túmulo, además de la mitra pontificia, aparece una tarja con las armas de Benedicto XIII. La referencia de la tiara, esta vez con una representación solar, se repite como remate de la estructura, subrayando la iconografía astral del túmulo.

La correspondencia entre las representaciones planetarias de la parte superior y los signos zodiacales del basamento, además de la vinculación con la musa correspondiente, fue perfectamente orquestada por el autor como queda expresado en el texto que la describe. Probablemente sea esta elaborada pira dominica la más cargada de sentido astral, simbolismo del que también participan el resto de aparatos festivos contemporáneos. Las alusiones solares se hacen absolutamente comunes en las exequias y fiestas de este momento en Manila, dedicadas tanto a beatos, como a gobernadores o monarcas. Junto a esta visión habría que subrayar el gusto por las alusiones florales, aunque al parecer esto fue más habitual en el plano literario que en las representaciones pictóricas.

La comparación entre el túmulo de Luis I y Benedicto XIII en Manila no permiten asegurar que existiera una reutilización de elementos generalizada,

25. Melpómene es la musa de la Poesía pero se le vincula habitualmente en el Barroco con la elegía y la poesía más concretamente funeraria. Como también cita la propia relación manileña el resto de musas acompañaban el lamento de Melpómene. De hecho la musa fue el centro también en las honras fúnebres de Gaspar de la Torre.

26. El pequeño Buen Pastor de tipo indoportugués está basado en la iconografía del Buda Maitreya. Hace referencia al pasaje bíblico Jn 2, 32-34, donde san Juan Bautista tiene la visión de la Trinidad. De todas formas la representación trinitaria no siempre está presente. Collin, FranCIS: «The Good Shepherd Ivory Carvings of Goa and their Symbolism» en Apollo, 1984, pp. 170-174.

27. El Sol en una brillante esfera en figura de un bellísimo joven, con el traje, que le da la común pintura, la diestra mano en acción de admirarse, y en la otra una tarja. Llanto de los astros en el ocaso del sol... op. cit. F. 51. 
lo que por otra parte, era habitual. Cabe la posibilidad de que las parejas de columnas salomónicas fueran reaprovechadas, como también ocurre con las numerosas tarjas donde se anotaban los poemas. Por último, en el tercer cuerpo aparece una figura que se lamenta, tema muy habitual en este tipo de estructuras. Melpómene llorando la muerte del monarca en este caso sobre un sitial, mientras que en otros casos aparece como una ninfa personificando Manila, dentro de una concha, lo que hace improbable la reutilización de la posible escultura, aunque es evidente que pervive la misma idea.

Existiera o no el material artístico reaprovechado, de lo que no cabe duda es de la reutilización de material a la hora de describir los túmulos. La comparación entre la de Benedicto XIII y la posterior de Gaspar de la Torre ofrece un paralelismo casi perfecto, haciendo alusión a los mismos tratadistas de arquitectura entre otros aspectos. Curiosamente estas alusiones a tratados también se encuentran en los mismos términos en México, aunque decantándose por opciones distintas. En América se cita dicha normativa arquitectónica para argumentar el uso del orden corintio como el más apropiado, mientras que en Filipinas se concluye que es mejor el dórico. ${ }^{28}$ Las dificultades técnicas de los artistas del archipiélago, unido a las prisas para celebrar las fiestas por el especial retraso con respecto al resto de los territorios hispanos, parecen estar en la justificación de la elección, aunque existan excepciones.

El caso excepcional hasta ese momento en Manila de Valdés y Tamón tuvo un continuador inmediato en su sucesor en el cargo, Gaspar de la Torre, quien ostentaría el puesto entre 1739 y 1745 , y que falleció en la capital del archipiélago. La ciudad, como sería lógico, organizó unas honras fúnebres en su honor que dieron lugar al menos a dos publicaciones, una de ellas incorporando el correspondiente grabado. ${ }^{29}$ Hasta ahora la imagen de la pira funeraria no había despertado interés, algo sorprendente por cuanto resulta importante para entender el desarrollo artístico de la ciudad en este momento. La descripción de la misma, además de explicar la ubicación de algunas de las pinturas, ofrece parcos pero interesantes datos sobre el conocimiento tratadístico-arquitectónico del momento. ${ }^{30}$ De todas formas esto solo sirvió para generar una pirámide escalonada donde ubicar los elementos propios de la cultura emblemática del momento, absoluta protagonista de la descripción.

La existencia de sencillas estructuras arquitectónicas, concebidas como soporte de un repertorio simbólico europeo, ha sido relacionada por algunos

28. Allo Manero, «Aportación al estudio», p. 134.

29. El primer caso destaca la recuperación de la figura de Melpómene, como en el caso de Benedicto XIII. Quintana, Domingo: Melpómene heroica en el cenotafio del muy ilustre Señor Don Gaspar de la Torre y Ayala, Manila, Universidad de Santo Tomás, 1746. Cortes Arredondo, Miguel José: Sermón funeral a la inmortal y amable memoria del muy ilustre Señor Don Gaspar de la Torre y Ayala, Manila, Compañía de Jesús, 1746.

30. El autor de la descripción dice que la estructura debía realizarse en orden dórico, ya que era el más adecuado para la ocasión, según se indicaba en autores como Cataneo o Vitrubio, a quienes cita expresamente. 
investigadores con soluciones de menor costo, erigidas en puntos distantes de la corte o de grandes templos catedralicios. ${ }^{31}$ Incluso podrían relacionarse con las estructuras escalonadas típicas de los altares sacramentales portugueses, de los que existen ejemplos en la propia Goa. Otro aspecto a destacar es el parecido existente entre la pira de Gaspar de la Torre y la levantada en México en memoria de Carlos II en 1701. En la capital filipina, como se ha visto, las novedades surgidas con las honras de Luis XIV (1717) habían llegado con lógico retraso, pero el caso del gobernador supone un paso atrás. Quizás se tratara de una estructura reutilizable, o quizás se considerara excesivo, simbólica y económicamente, erigir un túmulo como el de Benedicto XIII para honrar a un personaje de la administración, por muy importante que fuera su cargo.

La pira en honor al gobernador De la Torre fue sobre todo un aparato donde desarrollar un amplio contenido literario. En comparación con otras exequias previas y posteriores en la ciudad, los artistas se limitaron a pocas pinturas y a la decoración. Especialmente destacables resultan las tarjas, hasta ahora de perfil ovalado y que aquí incorporan la forma octogonal. Este cambio debe ponerse en relación con lo que se viene imponiendo en la decoración de las fachadas de las iglesias filipinas, que pasan del modelo de San Francisco de las Lágrimas al ligeramente posterior de las iglesias de Santa Ana de Sapa, o Malate. Algo similar puede decirse del frente de altar que aparece en el grabado, cercano decorativamente a otros conservados hoy en el Museo de San Agustín de Manila, que permanecían sin datación concreta.

Desgraciadamente, la escasez de representaciones afectó a los emblemas, que fueron mayoritariamente escritos. Aún así, los referentes literarios europeos pueden tratar de identificarse a partir de los datos aportados por la propia descripción. ${ }^{32}$ Por ejemplo, parece probable el uso del Sebastián de Covarrubias en la azucena rodeada de un seto, o incluso del propio sol eclipsado que había servido de referencia central a las exequias de Carlos II en México. Algo similar puede decirse del libro de Ortí, del de Zárraga o de otros con más difusión de los que beben tanto los filipinos como los peninsulares, que pueden vincularse con la representación del Fénix entre llamas, o de la Rosa cercada por hierbas respectivamente. Lamentablemente, la carencia total de detalles de estos emblemas impide hacer una vinculación segura con cualquiera de los autores mencionados. ${ }^{33}$

31. Mínguez, Víctor: «Efímero Mestizo» en AA. vv.: Iberoamérica mestiza. Encuentro de pueblos y culturas, Madrid, SEACEX, 2003.

32. Se hace referencia concretamente a los siguientes: «2. Una alusión de la azucena entre las espinas, que se pintó saliendo de un corazón, que exaltaba una cruz. 3. La muerte llena de ojos, aludiendo a lo que se vencía su Paciencia. 4 Una torre de superior grandeza, con una antorcha refulgente por corona. 5. Un sol eclipsado». Puede que la «muerte llena de ojos» sea una reinterpretación de los emblemas de Argos con cien ojos, pero aplicados a la muerte.

33. Horozco y Covarrubias, Sebastián de: Emblemas morales, Segovia, Juan de la Cuesta, 1591. Ortí, Marco Antonio: Siglo cuarto de la conquista de Valencia. A sus muy ilustres señores Jurados, Racional, Síndicos, y escribano...,Valencia, Juan Bautista Marzal, 1640. ZÁrragA, Francisco de: Séneca, juez de sí mismo, impugnado, defendido y ilustrado, Burgos, Juan de Viar, 1684. 
Aun así, determinados motivos hacen pensar que los eruditos del archipiélago no solo siguieron literalmente los modelos expuestos por las fuentes europeas sino que añadieron elementos de su propia inventiva. ${ }^{34} \mathrm{El}$ descenso de las representaciones puede explicarse por la imposición de una cierta austeridad en estas pompas, o por la dificultad que entrañaba contratar pintores de suficiente calidad para abordar la imitación de materiales y el repertorio emblemático propio de los túmulos. Por otra parte, la selección de pinturas ahonda en el carácter solar del programa iconográfico. ${ }^{35}$ Parece evidente que la imagen madurada durante el gobierno de Valdés se mantuvo, e incluso se potenció por parte de su sucesor.

Dicho esto, la muerte de Gaspar de la Torre en el cargo fue un caso excepcional en muchos sentidos. Su sucesor, Juan de Arechederra fallecería en Nueva Segovia un año después de dejar el puesto. Más tarde, el marqués de Ovando moriría en su vuelta a Nueva España. Habría que esperar a Pedro Manuel de Arandía Santiesteban para encontrar un gobernador que muriera en el cargo, en 1761, pero desgraciadamente aún no se ha localizado la documentación de sus honras fúnebres.

Como se viene mostrando, la documentación sobre exequias en Manila durante el siglo XviII permite trazar una evolución con pocos saltos debido al enorme desarrollo que vivió la imprenta en la ciudad y la mayor calidad de los grabadores según avanzaba el siglo. Modificando el tono y los temas, tanto fiestas como exequias bebieron del lenguaje artístico propio del momento. Así, se puede observar cómo la arquitectura efímera refleja los avances de la arquitectura de la ciudad. Tras una primera etapa marcada por la escasez de profesionales en la materia, la década de los cincuenta llevará aparejada la llegada de arquitectos como Juan de Uguccioni o el propio marqués de Ovando. A partir de este momento, como se observa en el túmulo de Felipe V, los modelos utilizados serán radicalmente distintos, subrayando el carácter clásico y marginando los follajes barrocos. En el aspecto pictórico y a tenor de las crónicas parece evidente que la ciudad contaba con profesionales hábiles en la pintura. Más allá de su calidad, su indudable actividad contrasta en primer lugar con la escasez de obras conservadas, explicable por las condiciones climáticas de la ciudad. Pero también contrasta con el relativamente escaso número de pinturas recogidas en los inventarios contemporáneos, quedando relegada la pintura en Manila a una actividad escasamente desarrollada y, en la mayoría de los casos conocidos, ejercida por pintores chinos.

34. Por continuar con el ejemplo de la azucena de Covarrubias, en este ejemplo se coloca naciendo de un corazón y una cruz.

35. En la descripción de las honras se cita expresamente cómo «en el frontis del primer cuerpo se pintó un Fénix entre llamas[...]. En el colateral derecho se puso la misma pintura[...]. En el colateral siniestro se pintó un Sol en el ocaso[...]. En el frontis del segundo cuerpo se pintó un Sol resplandeciendo[...]. En el colateral derecho de dicho frontis se pintó una Rosa cogida de una mano[...]. En el izquierdo colateral se pintó una rosa cercada de hierbas[...]. En el frontis del tercero cuerpo se pintó a la Fama». En el resto se pintaron distintos poemas funerarios, epígrafes, octavas, décimas, etc., a excepción de «los colaterales de este [último] cuerpo, y el último se adornaron con varias tarjas en que estaban pintados huesos y calaveras». 
Esta situación filipina debe compararse con la que presentaba la vecina corte virreinal portuguesa en Goa. Desde poco después de su fundación en el siglo XVI, el gobierno de la ciudad empezó a desarrollar un interesante aparato festivo vinculado con la vida de los reyes, donde los virreyes, desde su entrada hasta su fallecimiento tenían un completo y reglado ceremonial. ${ }^{36} \mathrm{El} \mathrm{momento}$ de apogeo vivido en la ciudad en sus primeros siglos de existencia fue, al parecer, sustituido por un cierto decaimiento cultural durante el siglo XVIII, si bien tal impresión puede ser consecuencia del escaso conocimiento que aún se tiene del fenómeno. ${ }^{37}$ Esto debió plasmarse con facilidad en las exequias regias celebradas no solo en Goa, sino en otros enclaves vecinos como Macao. Desgraciadamente, el estudio sobre este tipo de celebraciones, especialmente desde una perspectiva histórico-artística, apenas se ha iniciado. ${ }^{38}$

Poco antes de que De la Torre falleciera en Manila, murió en 1742 en ejercicio de su cargo el virrey de Goa Luis de Meneses (1717-1720 y 17401742) y se celebraron también públicas exequias. ${ }^{39}$ En 1750 falleció en Lisboa el obispo Nuno da Cunha de Ataíde, y sus exequias fueron recogidas en una publicación de la Inquisición de Goa aparecida en la capital portuguesa. ${ }^{40}$ En el mismo año muere el rey portugués João $\mathrm{V}$, si bien no sería hasta el año siguiente cuando tuvieran lugar en Goa tanto sus exequias como el juramento al sucesor José I. Desgraciadamente las referencias a estas celebraciones habían sido escasas, lo que dificultaba poner en relación el ámbito de Goa con el de Manila. No obstante, por los datos recogidos puede asegurarse que en todos los casos fue habitual recurrir a la emblemática para ilustrar, gráfica y conceptualmente, las variadas soluciones arquitectónicas que centraron todos los festejos.

Las honras fúnebres en memoria del virrey Meneses generaron dos textos diferentes: uno relativo a los sermones y otro a los emblemas que se compusieron para la iglesia jesuita del Bom Jesus. La publicación de los textos en Lisboa deja clara la intención de perpetuar en la metrópoli la memoria del difunto y los correspondientes fastos. Hay que recordar que el virrey murió repentinamente en pleno proceso de reformas impulsadas desde la capital lusitana. En este caso no hay referencias explícitas a la existencia de un túmulo funerario, sino simplemente a un aparato artístico-literario basado en la

36. Madeira Santos, CatArina: Goa é a chave de toda a India: perfil político da capital do Estado da India, 1505-1570, Lisboa, CNCDP, 1999.

37. Mártires Lopes, Goa Setecentista.

38. Para el caso de Macao pueden citarse los textos de Jerez Sabater, Pablo: «Portugal e Oriente a través da festa régia: as aclamaçoes de D. Joao IV em Goa e Macau» contribución al congreso Portugal, a Europa e o Oriente. Circulaçao de Artistas, Modelos e Obras, Lisboa, 2010. Luengo, Pedro: «Fiestas por el recibimiento en Macao de las reliquias del mártir André Cochinchina (1644)» en Huarte de San Juan, n. ${ }^{\circ} 15$, 2008, pp. 211-221. Además, las honras a José I fueron publicadas por MÁrtires López, Goa Setecentista.

39. Oraçao fúnebre nas exéquias...D. Luiz de Menezes, Biblioteca de la Universidad de Coimbra, Misc. 196, n. ${ }^{\circ}$ 3358. Emblemas, e poesias...[n]as exequias...[de] D. Luiz de Menezes, Misc. 271, n. ${ }^{\circ} 4505$.

40. Descripçao fúnebre das exequias... à memória [de] Nuno da Cunha de Ataíde, Biblioteca de la Universidad de Coimbra, Misc. 311, n. 5132. 
tradición emblemática. En el texto, carente de material gráfico, se relacionan las veintidós pinturas que «adornaron la Casa Profesa». ${ }^{41}$

Como viene poniéndose de manifiesto en últimos estudios, la tradición emblemática no tuvo en el ámbito portugués la fuerza que alcanzó en España, o en otros territorios europeos..$^{42}$ Esto se observa claramente en el número ciertamente escaso de publicaciones históricas sobre el tema conocidas hasta hoy. Este aparente desinterés solo podía nivelarse con la importación de textos ilustrados desde el resto de Europa, problema que aún está por conocerse en profundidad, más allá de la traducción de Alciato, vía Diego López, en 1695. De lo que no cabe duda es de que Goa en el siglo xvili apostó por su uso, seguramente a partir de fuentes españolas y, en menor medida, europeas.

Un ejemplo destacado lo ofrece el uso de Alciato, que puede rastrearse en la representación de Mercurio indicando el camino a unos caminantes (VIII), del Cordero y la zorra (LXVI), Hércules con las cadenas saliendo de su boca (CLXXX). ${ }^{43}$ De la misma forma parece conocerse el texto de Covarrubias en las referencias al Árbol de Bálsamo, o de la Hoguera; de Saavedra en la Brújula indicando la Estrella del Norte. ${ }^{44}$

La escasez de detalles arquitectónicos en la descripción de las honras del virrey contrasta con la variedad de ellas ofrecidos en la correspondiente a la muerte de Cunha de Ataíde ${ }^{45}$ Como no podía ser de otra forma, las celebraciones se llevaron a cabo en la iglesia de Santo Domingo, decorada al completo con

41. Los emblemas pintados que se citan son los siguientes: «1. Hum Tumulo, e de fronte Gentios, e Christaos, Capitaens, e Soldados chorando, e dando finaes de sentimento. 2. Huma bomba rebentando, e alguns homens cahindo feridos, e mortos. 3. Sol pondo-se no Horizonte com grande clarao. 4. No Mar huma concha aberta, e nella huma Perola. 5. De huma parte a morte cortando com huma fouce varias insignias militares, e da outra parte a Fama apanhando-as com a mao direita, e tocando huma trombeta com a esquerda. 6. A morte a cavalo, acommettendo com huma lança a hum Cavaleiro de Christo, sentado, e desarmado, porem as armas estavao junto delle. 7. O Sol inclinando para o Ocaso, huma Nao, e junto della Regulo Attilio, o qual estava afastando com a mao a seus amigos, e parentes, que lhe pertendiao impedir a viagem para o desterro. 8. Cezar coroado de louro com a espada na mao direita, e com a pena na esquerda. 9. O fogo subindo em labaredas. 10. Huma agulha de marear buscando a estrela do Norte. 11. Mercurio com azas nos hombros, e pes, apontando com o seu Caduceo para o Ceo, e olhando para hum homem, com quem lhe mostra o caminho. 12. Hum exercito, que hia virando as costas, e fugindo com alguns Soldados feridos, e outros mortos, e da outra parte pintouse outro exercito capitaneado por Cesar, o qual hia vencedor, e sguindo o vencido. 13. O Sol no Zodiaco, e nelle os Signos Celestes. 14. Hercules, sahidolhe da boca humas cadeas de Ouro, e prezos com ellas a hum lado alguns homens. 15. Hum caçador cortando a cabeça com a espada a huma Serpente, e matando-a na sua mesma cova. 16. O Sol no Ceo claro, e escuro, e abaixo a terra, e nella homens, brutos, arvores, flores, e metaes. 17. O mar alterado, e tempestuoso, e nelle hum grande penedo, ou rocha resistindo à furia das ondas. 18. O Sol no seu Occazo, e a Morte cortando com a fouce hum Gyrasol, o qual estava inclinado para o Sol. 19. A Justiça que he huma mulher com a balança na mao esquerda, e com a espada na direita. 20. Hum Cordeiro, e hum rapaz, açoutando-o com humas varas. 21. Huma Arovre de balsamo, e hum homem ferindo-a com hum machado. 22. Marte com a espada na mao, affugentando os outros Planetas».

42. Amaral, Rubem Jr.: Emblemática lusitana e os emblemas de Vasco Mousinho de Castelbranco, Lisboa, Centro de História da Universidade de Lisboa, 2005.

43. Alciato, Andrea: Emblemas, Ed. Sebastián, Santiago, Madrid, Akal, 1985. 1642 .

44. SaAvedra Fajardo, Diego De: Idea de un príncipe político cristiano (Empresas políticas), Milán,

45. Descripçao funebre das exequias que a Inquisiçao de Goa dedicou a memoria do ... Nuno da Cunha de Ataide... Lisboa, S. Oficio, 1753. 
colgaduras y emblemas. ${ }^{46}$ En un primer momento podría haberse interpretado el caso de Meneses como una excepción a lo que sería habitual en el ámbito portugués, pero las exequias de Cunha de Ataíde inciden en este conocimiento de la literatura emblemática. De nuevo Covarrubias puede identificarse en la referencia al heliotropo o a la espada en la mano, mientras que Saavedra parece utilizado en la Luna con una noche oscura, o Lorea en la imagen del Vesubio. ${ }^{47}$

En el crucero del templo dominico se instaló un gran túmulo funerario de planta cuadrada de casi ocho metros y medio de altura y seis de lado. Sobre esta base se desarrollaban dos cuerpos de arquitectura. Toda la estructura estaba decorada con costosos paños que hacían imitación de mármoles y bronces. En cada frente del primer cuerpo se ubicaban sendas tarjas pintadas donde se leían los epitafios. En correspondencia con ellas, en el segundo cuerpo se ubicaron un retrato, en la cara exterior, las armas de la familia Cunha, en la interior, y en las dos laterales, las del Santo Oficio y el difunto. Seguramente en este cuerpo se cobijaba el féretro cubierto por un rico paño y una almohada donde reposaba el bonete. Rematando toda la estructura se colgó del techo una corona de donde pendía el dosel que era sustentado por esculturas de ángeles que lo enlazaban con los pilares del templo.

El análisis de las honras funerarias mencionadas permite efectuar algunas consideraciones generales sobre el tema. La cultura emblemática mantenía un lugar preponderante e incluso los modelos utilizados fueron los mismos en una y otra ciudad. De la misma forma, en una fecha similar como la que plantean las honras de dos eclesiásticos como Benedicto XIII (1733) y Cunha de Ataíde (1753), los modelos son relativamente cercanos. Otro elemento homogéneo a destacar es el grado de simpleza que a priori ofrecen estas estructuras y celebraciones, donde la referencia a lo local es prácticamente inexistente, frente a lo que ocurría en México.

A estas convergencias hay que añadir algunas diferencias importantes entre la realidad indiana y la filipina. Al menos en el túmulo del inquisidor, la estructura arquitectónica es de base cuadrada, frente al gusto general por la planta octogonal existente en Manila. De la misma forma, parece que las grandes estructuras de templo que empezaron a hacerse en Manila a partir de la muerte de Felipe $\mathrm{V}$ tardaron más en aceptarse en la ciudad portuguesa. Estos desfases muestran la circulación de modelos artísticos en el ámbito hispano,

46. Los emblemas fueron colocados a los largo del templo y se describen solo algunos de ellos: «A sua Religiao em huma carvalho em outeiro[...]. O amor de Deos em o monte Vesuvio ardendo[...]. A esperança em Deos em hum gyrasol[...]. A resignaçap em Deos em hum navio em tormenta, e hum coraçao em sima delle[...]. A sua justiça em huma luz em linha recta do Cea a terra. A sua misericordia em hum braçp com huma espada na mao. A caridade para com os pobres em hum poço, com baldes em sima do seu arco. A sua liberalidade em huma roma aberta espalhando seus bagos. A sua igualdade em materias da Fé em huma véla accesa no meio de huma casa. O seu segredo em hum relogio de area. A sua constancia em huma estrella cingida de hum arco de nuvens. A sua prudencia na Lua luzindo em huma escura noite. A sua protecçao em hum castello. A sua piedade em huma palma. A sua sabedoria en hum livro aberto, e escrito. O ser pacificador em huma pomba, tendo na boca hum ramo de oliveira». Ibídem. Ff.7-8.

47. Lorea, Antonio DE: David pecador, empresas morales, politico cristiana, Madrid, Francisco Sanz, 1674. 
gracias, por un lado, al desarrollo cultural alcanzado por la capital novohispana en este momento y, por otro, al grado de desarrollo de un galeón de Manila que poco a poco dejaba atrás los continuos naufragios y ataques.

De lo que no cabe duda es que Manila y Goa se caracterizaban en estas décadas del siglo XVIII por ser ciudades muy cosmopolitas. Aunque la documentación oficial esquiva el asunto, otro tipo de referencias contemporáneas hacen alusión a la presencia de europeos en la ciudad, incluso como principales responsables de la toma británica de Manila en 1762. Además de informar sobre el galeón y sobre la política local, seguramente se difundieron los fastos que la ciudad dedicaba a monarcas, gobernadores e incluso religiosos de distinto orden. Si el carácter propagandístico cara a la metrópoli parece indiscutible, las ediciones de fiestas en Goa que se hicieron en Lisboa, son testimonios de una peculiar imagen del poder que se intentaba ofrecer dentro de un contexto marcadamente heterogéneo desde el punto de vista cultural. 


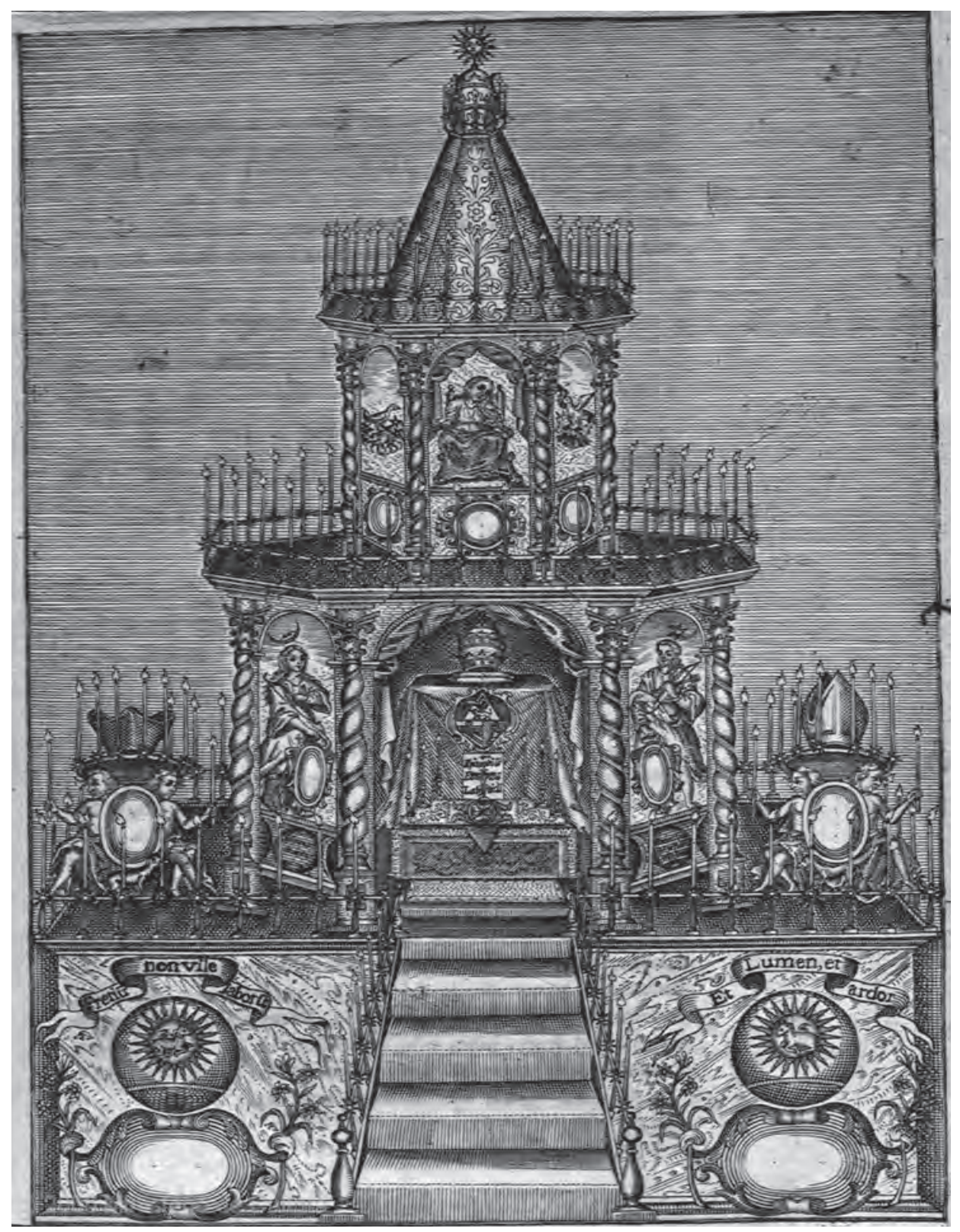

Fig.1.Túmulo en honor a Benedicto XIII en Manila 


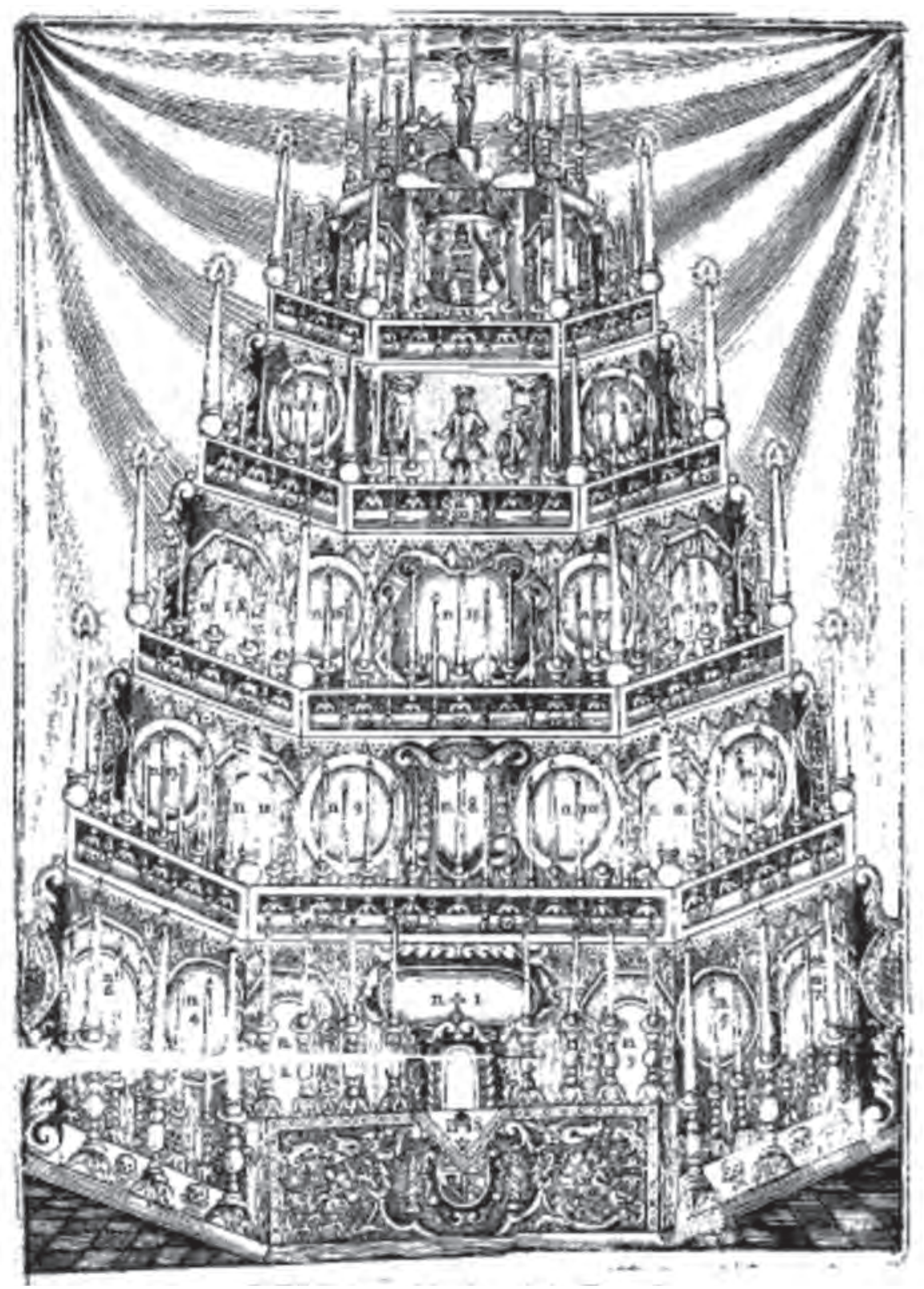

Fig. 2. Túmulo del gobernador Gaspar de la Torre en Manila 